\title{
A coleta seletiva remunerada de resíduos domésticos: um modelo de sustentabilidade ambiental e econômica para os municípios brasileiros
}

Revista Brasileira de Tecnologias Sociais

*Administradora de Empresas, Mestranda em Gestão de Políticas Públicas, UNIVALI.

${ }^{* *}$ Doutor em Sociologia Política pela UFSC. Coordenador do Mestrado Profissional em Gestão de Políticas Públicas da UNIVALI.

\section{Paid selective collection of domestic waste: \\ a model of environmental and economic sustainability for the brazilian municipalities}

\author{
Marinês de Pauli Tomaz*; Flávio Ramos***
}

Resumo: Este artigo avalia os modelos atuais de coleta de resíduos domésticos implantados, aponta as suas deficiências e propõe a adoção de um novo modelo de coleta seletiva, baseado na remuneração do cidadão pela quantidade de material por ele recolhido e entregue. A metodologia empregada abrange a pesquisa qualitativa sobre os atuais modelos de coleta implantados, bem como a pesquisa quantitativa sobre os atuais volumes de resíduos recolhidos e os respectivos custos operacionais associados. O escopo de pesquisa deste projeto restringiu-se somente aos processos de coleta e tratamento de resíduos domésticos. O resultado consiste na criação de um modelo de gestão municipal de resíduos domésticos, o qual possa ser implantado como política pública em qualquer município brasileiro e que seja sustentável economicamente e ambientalmente.

Palavras-chave: Coleta Seletiva. Sustentabilidade. Resíduos Domésticos.

Abstract: This article evaluates the current models for collecting household waste in place, pointing their shortcomings and proposes the adoption of a new model of selective collection, based on the citizens pay the amount of material collected and delivered by him. The methodology covers the qualitative research on current models of implanted collection as well as quantitative research on current volumes of waste collected and their associated operating costs. The scope of this research project will be limited to only the processes of collection and treatment of household waste. The expected outcome of this project is to create a model of municipal domestic waste management, which can be deployed as a public policy, and in any Brazilian city that is sustainable economically and environmentally.

Keywords: Waste Recycling. Sustainability. Household Waste. 


\section{INTRODUÇÃO}

Segundo os últimos dados divulgados pelo Instituto Brasileiro de Geografia e Estatística - IBGE (2013), referentes ao censo demográfico de 2010, cerca de $85 \%$ da população brasileira vive em comunidades urbanas, com tendência de crescimento desta porcentagem para os próximos anos. Paralelamente, a infraestrutura urbana não foi ampliada na mesma proporção deste crescimento. Esta crescente demanda impõe aos nossos governantes o desafio de conciliar desenvolvimento econômico e populacional com a sustentabilidade ambiental. A qualidade do ar, o manejo das águas pluviais, a ocupação irregular de áreas de preservação, o saneamento básico, a coleta e o tratamento de resíduos sólidos são alguns exemplos de Políticas Públicas relacionadas à Sustentabilidade Ambiental.

Romeiro (2011) define que o desenvolvimento sustentável deve ser "economicamente sustentado" (eficiente), “socialmente desejável” (includente) e "ecologicamente prudente" (equilibrado). Cita que são necessárias políticas públicas específicas para se evitar que o desenvolvimento econômico beneficie apenas uma minoria; da mesma forma, o equilíbrio ecológico pode ser afetado negativamente pelo crescimento econômico, caso não haja políticas "prudentes" que estimulem o aumento da eficiência ecológica e reduzam o risco de perdas ambientais. Para Jacobi (2003), o tema da sustentabilidade confronta-se com o paradigma da "sociedade de risco", a qual surge com a globalização, a individualização, o subemprego e a difusão dos riscos globais, implicando a necessidade de se multiplicarem as práticas sociais baseadas no acesso à informação e à educação ambiental.

Finalmente, o escopo de pesquisa deste projeto, dentro do âmbito destas políticas, restringir-se-á aos processos de coleta e tratamento de resíduos domésticos.

\section{A SOCIEDADE PRODUTORA DE RESÍDUOS}

O tema Coleta Seletiva Remunerada não é inédito: iniciativas municipais já foram anunciadas e implementadas anteriormente. Entretanto, o modelo a ser proposto difere dos atuais divulgados, nos quais é pressuposta a participação voluntária do cidadão ou por meio do serviço de coleta prestado por comunidades de catadores autônomos, dentro do conceito de "Economia Solidária”. A proposta desta pesquisa é desenvolver um modelo de gestão municipal de resíduos domésticos, baseado no conceito de "Logística Reversa" e no princípio de que "quem gera o resíduo deve dar destinação sustentável a ele”. Neste modelo, o próprio cidadão seria estimulado por meio de um incentivo financeiro a ser dado pela respectiva prefeitura, a realizar a coleta seletiva de resíduos domésticos, sejam sólidos, líquidos ou orgânicos, e a entregá-la em postos de coletas preestabelecidos, arcando com a despesa de transporte da mesma. Em contrapartida, o executivo municipal remuneraria este, proporcionalmente ao peso do material entregue e pelo valor específico de cada tipo de material, por meio da concessão de créditos, uma espécie de "moeda virtual”. Estes seriam "consolidados" numa conta individualizada do cidadão, a qual poderia ser acessada por meio de um "cartão cidadão” de âmbito municipal. Os créditos poderiam ser utilizados, por exemplo, no desconto de valores do Imposto Predial e Territorial Urbano (IPTU), nas compras em "sacolões" de hortifrutigranjeiros e mercados municipais, no transporte e nos estacionamentos urbanos, dentre outros serviços disponíveis localmente.

Um dos maiores desafios da humanidade, daqui por diante, é dar um destino sustentável a todo o lixo doméstico produzido diariamente no planeta, principalmente nos grandes centros 
urbanos, onde concentra a maior parte da população: mais de 70\% no mundo, segundo Hogan (1997), e mais de $85 \%$ no Brasil, segundo IBGE (2013), ambos com tendência de crescimento. O aumento do volume de lixo produzido, além de estar correlacionado com a aglomeração populacional nas cidades, está diretamente relacionado com o aumento do Produto Interno Bruto (PIB) destas sociedades: “quanto maior a riqueza gerada, maiores serão os volumes de resíduos produzidos”. O lixo domiciliar brasileiro possui cerca de 30\% de materiais que podem ser reciclados (IBGE, 2002).

No Brasil, são produzidos, todos os anos, cerca de 83 milhões de toneladas de lixo, dos quais apenas 40,5\% têm destinação adequada (36\% para aterros sanitários, 3\% para compostagem, 1\% reciclado por separação manual e $0,4 \%$ para incineração). Como agravante, há que se destacar que uma parcela considerável do lixo produzido não é nem sequer coletado, sendo disposto de maneira irregular em ruas, rios, córregos e terrenos vazios. Isto pode levar a problemas como o assoreamento de rios e o entupimento de bueiros, com consequente aumento de enchentes nas épocas de chuva, além da destruição de áreas verdes, mau cheiro, proliferação de moscas, baratas e ratos, todos com graves consequências diretas ou indiretas para a saúde (AMORIN et al., 2009, p. 31).

Apenas 14\% dos municípios brasileiros desenvolvem programas de coleta seletiva de resíduos domésticos (CEMPRE, 2012). Em geral, os programas municipais de coleta seletiva são implantados com recursos orçamentários municipais, oriundos da taxa de limpeza pública ou da taxa de arrecadação do Imposto Predial e Territorial Urbano (IPTU), o qual tem base de cálculo na área edificada do imóvel do contribuinte. Até o momento, nenhuma experiência de tarifação de resíduos sólidos domésticos, baseada na pesagem do material coletado, foi anunciada no Brasil, a exemplo de alguns países da Europa e Estados Unidos (RIBEIRO; BENSEN, 2006).

Para Campos et al. (2009, p.6), a reciclagem não deve ser vista como a principal solução para o lixo, mas como um elemento dentro de um conjunto de soluções ambientais. Para Monteiro et al. (2001, p. 120), a reciclagem mais eficiente de resíduos domésticos é aquela que é realizada pelo próprio cidadão, na sua própria casa, por meio da limpeza e da separação dos mesmos. Já o material reciclável, que é misturado ao lixo comum, fica sujo e contaminado (terra e gordura, entre outros), tornando o beneficiamento deste mais dispendioso e complexo. Quando separado numa usina de reciclagem por meio de processos manuais e eletromecânicos, a eficiência deste processo é de apenas 3\% a 6\% em peso, dependendo da sofisticação tecnológica empregada.

No relatório da Fundação Nacional de Saúde (FUNASA, 2010), a coleta de materiais recicláveis, encaminhados para as centrais de triagem, é realizada segundo diferentes modelos: exclusivamente pelas prefeituras, pelas prefeituras em conjunto com as cooperativas/associação de catadores ou exclusivamente pelas cooperativas/associações. Em algumas cidades, os recicláveis são coletados "porta a porta”, em dias diferentes da coleta de lixo comum; em outras, são utilizados os sistemas de entrega voluntária.

Segundo o Fundo das Nações Unidas para a Infância (UNICEF), em 2000 estimava-se que, no Brasil, mais de 40 mil pessoas viviam diretamente da catação em lixões e mais de 30 mil nas ruas, constituindo-se em sua única opção de renda (ABREU, 2001). Hoje, algumas estimativas apontam para mais de 200 mil pessoas. A organização de catadores de lixo em associações ou cooperativas de trabalho segue os preceitos da "Economia Solidária". Entretanto, o cerne desta economia é o conceito de "autogestão", para o qual Singer (2002, p. 9) resume como "ninguém manda em ninguém” ou "todos mandam iguais”. A prática da autogestão exige esforços adicionais, porque, além das tarefas rotineiras, existe a preocupação com os problemas gerais da empresa, o envolvimento em conflitos interpessoais e a participação em reuniões cansativas. Desta forma, 
(...) os problemas mais comuns detectados nessas iniciativas, que desafiam a continuidade dos atuais programas de coleta seletiva, incluem os de ordem organizacional das cooperativas, a fragilidade e dependência da relação das cooperativas com o poder público, a crise atual de diminuição das quantidades de material coletado pelas cooperativas, […]. (FUNASA, 2010, p. 122-123).

Por fim, as estatísticas demonstram que o volume de resíduos coletados e reciclados está aquém do potencial que é gerado, sendo grande parte deste desperdiçado em lixões ou aterros sanitários. O lixo domiciliar brasileiro possui cerca de 30\% de materiais que poderiam ser reciclados (IBGE, 2002).

\section{O MODELO DE COLETA SELETIVA REMUNERADA}

DE RESÍDUOS DOMICILIARES

O modelo é composto de quatro entidades ou participantes: o Cidadão, a Prefeitura, o Coletor e o Reciclador. Opcionalmente, os papéis do Coletor e do Reciclador poderão ser desempenhados pela própria Prefeitura. A dinâmica do processo é a seguinte:

(a) O cidadão solicita o seu “cartão-cidadão” junto à Prefeitura. Por meiodeste cartão, é implementada uma espécie de "moeda virtual” do município, no qual os créditos oriundos da coleta seletiva de resíduos domiciliares são depositados e podem ser usados para o abatimento de despesas ou tarifas de serviços municipais, tais como transporte público, IPTU, sacolões de hortifrutigranjeiros, entre outros;

(b) Uma vez de posse do cartão, o cidadão estará apto a realizar transações de crédito, por meio da entrega de resíduos domiciliares (orgânicos e recicláveis) nos Postos de Coleta determinados pela Prefeitura/Coletor, ou realizar transações de débito no cartão (se houver saldo disponível), por meio do pagamento de impostos ou serviços municipais;

(c) Com relação aos resíduos domiciliares produzidos (orgânicos e recicláveis), os mesmos poderão ser recolhidos de acordo com as seguintes alternativas:

i. Na primeira alternativa, o cidadão contrata, junto à Prefeitura, o serviço de coleta domiciliar de resíduos orgânicos e, opcionalmente, de resíduos recicláveis também. O inverso não é válido: não seria possível a contratação exclusiva do serviço de coleta para resíduos recicláveis, sem a coleta dos resíduos orgânicos. Nesta forma, cada tipo de resíduo requererá uma lixeira exclusiva. O custo deste serviço, para o cidadão, estará relacionado com o volume de resíduos domiciliares produzidos por este, proporcional ao tamanho das lixeiras contratadas: quanto maior a lixeira, maior o custo do serviço contratado. A fim de racionalizar o gasto operacional do serviço de coleta domiciliar para a Prefeitura, o mesmo não operaria todos os dias, como frequentemente ocorre nas cidades brasileiras, mas em alguns dias da semana. Desta forma, o volume da lixeira a ser contratada deve possuir capacidade de estocagem suficiente para o período entre coletas. Como as lixeiras teriam tamanhos padronizados, a implantação de sistemas de "coleta automatizada", por meio de caminhões equipados com "braços hidráulicos”, operados por um único funcionário (motorista), capazes de descarregar o conteúdo destas diretamente na caçamba, sem manipulação humana, seriam totalmente factíveis de serem implementados.

ii. Nesta alternativa, o cidadão fica responsável pela coleta e pela separação, para orgânicos e recicláveis, e limpeza, para recicláveis, dos resíduos domiciliares produzidos, bem como o 
transporte e a entrega dos mesmos nos Postos de Coleta designados pela Prefeitura/Coletor. Para esta alternativa, o cidadão passa a receber créditos no seu “cartão-cidadão”, proporcionais ao peso e à natureza do material entregue. Os materiais recicláveis (metais, vidro, papel, plástico, entre outros) terão seus valores definidos pelo preço de mercado comercializado pela Prefeitura/ Reciclador. Os resíduos orgânicos terão o menor valor por quilo atribuído, como forma de incentivo para que o cidadão realize a coleta seletiva dos materiais recicláveis e evite que os mesmos sejam misturados e destinados incorretamente para "lixões" ou aterros sanitários, o que causaria, além dos problemas ambientais já conhecidos, a saturação precoce destes.

(d) Estrategicamente, por ser a primeira alternativa (a coleta domiciliar contratada) a menos sustentável ambientalmente, pois exige que uma frota de caminhões circule, poluindo o ar por meio da queima de óleo diesel e degradando a já comprometida mobilidade urbana das grandes cidades, e que também compromete a sustentabilidade econômica dos municípios, por meio do crescente volume de resíduos produzidos pela população e o crescente aumento de custos de transporte e destinação final destes, o preço final do serviço a ser cobrado do cidadão deverá ser majorado, a fim de desestimular a adoção deste em prol da segunda alternativa (a coleta seletiva remunerada), sustentável ambientalmente e economicamente;

(e) Finalmente, após os resíduos serem coletados nos domicílios ou entregues ao Coletor, o mesmo se encarregará pela logística de armazenamento temporário e transporte destes até o Reciclador, o qual se encarregará de processar os resíduos e comercializá-los, tanto para os recicláveis, quanto para os orgânicos (compostagem ou biogás);

(f) O diagrama que representa o Modelo de Coleta Seletiva Remunerada de Resíduos Domiciliares, utilizando-se da notação da metodologia BPM (Business Process Modeling) (ver Anexo I).

\section{CONSIDERAÇÕES FINAIS}

Diante do cenário exposto anteriormente, pode-se concluir que o atual modelo de coleta seletiva de resíduos domésticos, baseado na centralização da triagem destes materiais em espaços dedicados para esta finalidade e mantidos pelas prefeituras municipais ou empresas terceirizadas, ou baseado no conceito de "Economia Solidária", por meio da implantação de associações/ cooperativas de catadores, não possui a eficiência necessária para o processamento do volume atual e futuro, de lixo doméstico produzido nos centros urbanos. Embora a organização dos catadores em associações/cooperativas propicie a estes uma melhoria na sua qualidade de vida, delegar a esta organização ou, em conjunto com a atual logística de coleta implantada pelas municipalidades, a exclusividade da coleta seletiva, não tem garantido uma gestão sustentável dos resíduos domésticos produzidos pela respectiva comunidade. Diversos são os casos de municípios, cujos "lixões" ou aterros sanitários apresentam saturação do espaço ocupado, bem como problemas de degradação ambiental e social decorrente disso.

O modelo proposto de coleta seletiva remunerada visa suprir as deficiências, aqui apontadas, dos atuais modelos já implantados, tais como o baixo volume de material reciclável coletado, a saturação precoce de lixões e aterros sanitários, além do alto e crescente custo operacional dos serviços de coleta pública municipais. Este modelo proposto, além de diminuir o volume de resíduos destinados aos aterros/lixões, propiciará a otimização da frota de caminhões destinada ao transporte deste material, economizando combustível e reduzindo a quilometragem 
percorrida, a poluição gerada pela queima de óleo diesel, o tráfego urbano e, consequentemente, o custo operacional do sistema. Além disso, a comercialização do material reciclável e orgânico (compostagem e biogás, por exemplo) renderia recursos financeiros que contribuiriam para a sustentabilidade econômica do sistema, incluindo os créditos para os cidadãos e a eventual queda na receita de impostos pelos municípios, em decorrência do uso destes créditos.

A implantação do modelo proposto é viável, principalmente, nos municípios que já possuem um sistema de coleta pública estabelecido e cujo custo operacional seja bancado pela arrecadação de impostos. Talvez, para os pequenos municípios, cujos volumes de resíduos domésticos gerados, de alguma forma, não viabilizem economicamente a adoção do modelo proposto, a recomendação seria, neste caso, a implantação de "consórcios municipais". Estes consórcios, os quais agregariam diversos municípios, gerariam volume de resíduos suficientes para propiciar o ganho de escala na logística e a otimização do sistema proposto, implicando a respectiva sustentabilidade econômica e ambiental do mesmo.

Por fim, por tratar-se de um tema estratégico, a sustentabilidade ambiental, a qual deverá ter prioridade sobre a sustentabilidade econômica, um “eventual” subsídio financeiro à operação do sistema proposto por parte das três esferas do poder executivo (municipal, estadual e federal), a título de "políticas públicas”, não deve ser descartada, em prol da aderência à legislação ambiental vigente e do Plano Nacional de Resíduos Sólidos (PNRS).

\section{REFERÊNCIAS}

ABREU, M. F. Do lixo à cidadania: estratégias para a ação. Brasília: Caixa, 2001.

AMORIN, L.; KUHN, M.; BLANK, V.; GOUVEIA, N. Saúde Ambiental nas Cidades. $\mathbf{1}^{\text {a }}$ Conferência Nacional de Saúde Ambiental. GT Saúde e Ambiente ABRASCO - 2009. Disponível em: <http://iah. iec.pa.gov.br/iah/fulltext/pc/ monografias/outros/txt_7832566.pdf>. Acesso em: 30 Jul. 2013.

CAMPOS, L. M. et al. A reciclagem como empreendedorismo: fonte de transformação socioeconômica e ambiental. 2009. Disponível em: <http://www.faccamp.br/ojs/index.php/RMPE/article/ download/47/37>. Acesso em: 29 mai. 2013.

CEMPRE - Compromisso Empresarial para a Reciclagem. Pesquisa Ciclosoft 2012. Disponível em <http://www.cempre.org.br/ciclosoft_2012.php>. Acesso em: 30 ago. 2013.

FUNASA. Programas municipais de coleta seletiva de lixo como fator de sustentabilidade dos sistemas públicos de saneamento ambiental na região metropolitana de São Paulo. Brasília, 2010. Disponível em: <http://www.funasa.gov.br/site/wp-content/files_mf/estudosPesquisas_ColetaSeletiva. pdf>. Acesso em: 29 mai. 2013.

HOGAN, D. J. Mudança ambiental e o novo regime demográfico. In: CAVALCANTI, C. (Org.) Meio ambiente, desenvolvimento sustentável e políticas públicas. São Paulo Cortez, 1997 p. 369-381.

IBGE - INSTITUTO BRASILEIRO DE GEOGRAFIA E ESTATÍSTICA. Atlas do Censo Demográfico 2010. 2013. Disponível em: <http://censo2010.ibge.gov.br/apps/atlas/>. Acesso em: 30 jul. 2013.

Pesquisa Nacional de Saneamento Básico - PNSB 2000. Rio de Janeiro: IBGE, 2002.

JACOBI, P. Educação Ambiental, Cidadania e Sustentabilidade. Cadernos de Pesquisa, n.118, 2003. Disponível em: <http://www.scielo.br/scielo.php?script=sci_ arttext\&pid=So10015742003000100008\&lng=en\&nrm=iso\&tlng=pt>. Acesso em: 17 set. 2013.

KLock, M.J.; Ramos, F. 
MONTEIRO, J. H. et al. Manual de gerenciamento integrado de resíduos sólidos. Rio de Janeiro:

IBAM, 2001. Disponível em: <http://www.resol.com.br/cartilha4/ manual.pdf>. Acesso em: 30 jul. 2013.

RIBEIRO, H.; BESEN, G. R. Panorama da coleta seletiva no Brasil: desafios e perspectivas a partir de três estudos de casos. Revista de Gestão Integrada em Saúde do Trabalho e Meio Ambiente, 2006. Disponível em: <http://www.revistas.sp. senac.br/index.php/ITF/article/viewFile/138/166 >.. Acesso em: 30 mai. 2013.

ROMEIRO, A. R. Desenvolvimento sustentável: uma perspectiva econômico-ecológica. 2011 1. Disponível em: <http://www.scielo.br/pdf/ea/v26n74/a06v26n74.pdf >. Acesso em: 24 set. 2013

SINGER, P. Introdução à economia solidária. São Paulo: Fundação Perseu Abramo, 2002. ISBN 8586469-51-3. 


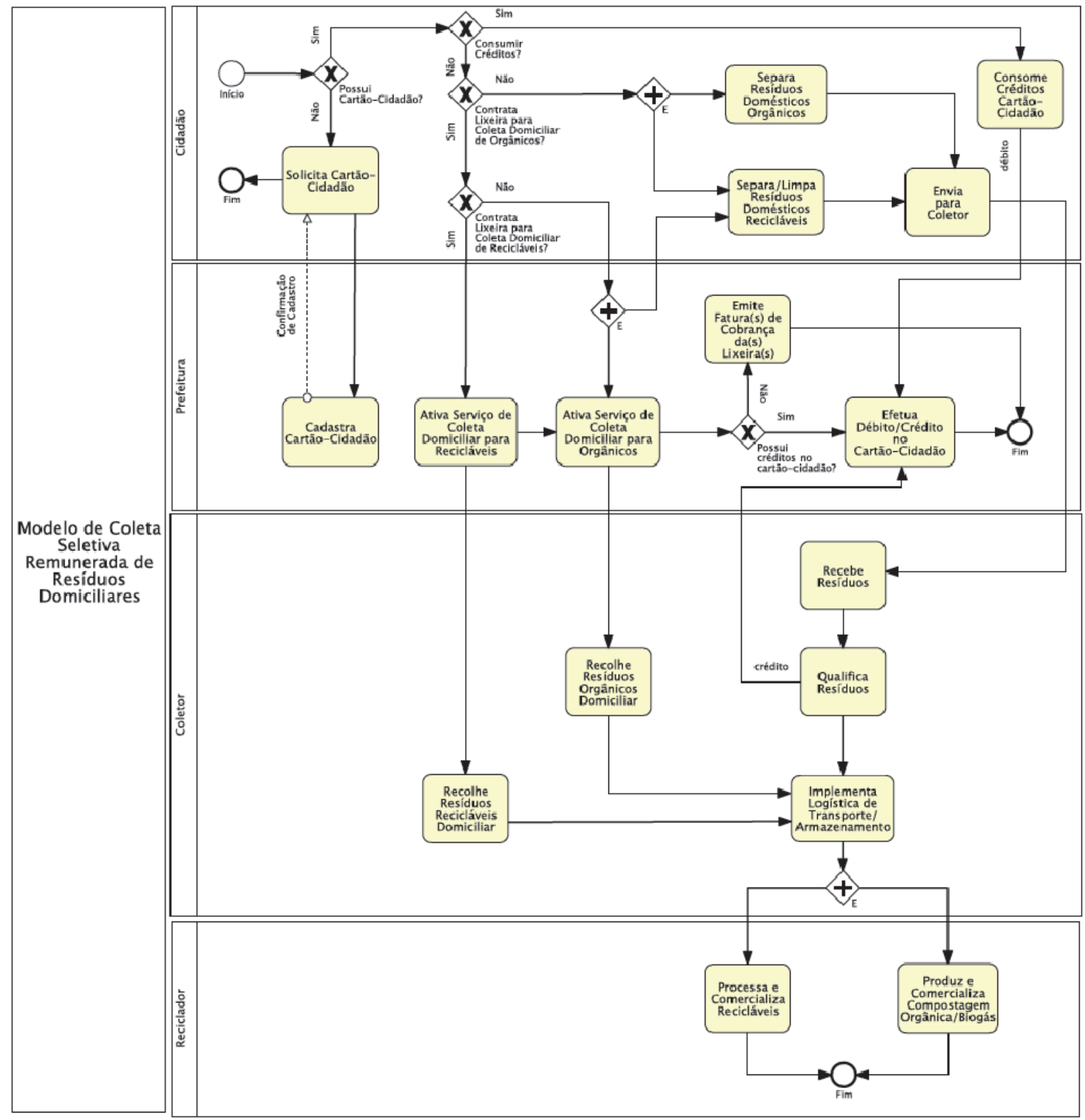

